\title{
Modelo de acumulación minero y territorio: trabajar y habitar*
}

\section{Modelo de acumulação das empresas de mineração e território: trabalhar e habitar}

\section{Mining Companies Accumulation Model and Territory: Working and Living}

\author{
Juan Carlos RODRÍGUEZ Torrent** \\ Patricio MEDINA Hernández ${ }^{* * *}$
}

\begin{abstract}
RESUMEN
Este trabajo discute las características generales del modelo de acumulación en minería y su impacto en el trabajo, en el territorio y en algunas trayectorias de los emplazamientos mineros, en relación a las distintas fórmulas empleadas para contener a los trabajadores y a la población en las ciudades ligadas a la explotación de yacimientos metálicos y no metálicos, específicamente en Chile. Se muestra cómo el capital opera con criterios de viabilidad/inviabilidad en relación a la rentabilidad, llegando a sacrificar centros urbanos completos, con consecuencias culturales y sociales que atentan contra las identidades, imaginarios y la territorialización.
\end{abstract}

Palabras claves: ciudades mineras; mega minería; ciclos mineros; trabajo.

\section{RESUMO}

Este trabalho discute as características gerais do modelo de acumulação na atividade mineradora e seu impacto no trabalho, no território e em algumas trajetórias das localidades em que se inserem, em relação às distintas fórmulas empregadas para conter os trabalhadores e a população nas cidades ligadas à exploração de depósitos metálicos e não metálicos, especificamente no Chile. Demonstra-se como o capital opera com critérios de viabilidade/inviabilidade em relação à rentabilidade, chegando a sacrificar centros urbanos inteiros, com consequências culturais e sociais que atentam contra as identidades, contra os imaginários e contra a territorialização.

Palavras-chave: cidades mineiras; mineração em grande escala; ciclos mineiros; trabalho.

\footnotetext{
"Este trabajo es parte del Proyecto Fondecyt 1095037, "Memorias, imaginarios y ruinas en ciudades de la utopía industrial: Lota y Taltal".

** Dr. en Antropología. Escuela de Diseño, Universidad de Valparaíso, Chile. Email: juancarlosrodriguezt@yahoo.com

**** Antropólogo. Escuela de Psicología, Pontificia Universidad Católica de Valparaíso, Chile. Email: pmedinahernandez@yahoo.es
} 


\begin{abstract}
This paper discusses the general characteristics of the accumulation in mining and its impact on working in the territory as well as some trajectories of mining sites in relation to the various formulas used to contain the workers and population in the cities linked to the exploitation of metallic and non-metallic deposits. It shows how capital operates with the criteria of feasibility/infeasibility in relation to profitability, coming to sacrifice entire urban areas, with cultural and social consequences that threaten identities, imaginaries and the territorialization.
\end{abstract}

Key-words: mining towns; mega mining; mining cycles; work.

\section{Antecedentes}

El paradigma extractivista presenta una larga y obscura trayectoria en Sud América. Esto lo podemos verificar en los enclaves coloniales donde probablemente lo más cercano y emblemático puede ser encontrado en Potosí, Bolivia (véase RODRÍGUEZ, 2002), lugar que por las magnitudes de la riqueza extraída en el pasado y la pobreza extrema del presente, al decir de Eduardo Galeano, bien merece una segunda oportunidad. Sabemos, y así lo indican todas las referencias históricas, que estos procesos extractivos han revelado toda la imagen desgarradora de los ciclos mineros, significando la destrucción de las economías locales y en los casos más extremos, han generado procesos y marcos laborales esclavistas y un empobrecimiento crónico de las poblaciones una vez agotados los recursos. Presentaremos aquí, los ejemplos más demostrativos de la minería chilena donde han ocurrido, y siguen ocurriendo, estas transformaciones; específicamente nos referiremos a las localidades mineras de extracción de nitrato: María Elena y Pedro de Valdivia, en el Norte Grande; la de carbón: Lota, en la Zona Sur; y la de cobre: Chuquicamata, en el Norte Grande (Figura 1). Todas ellas son antonomásicas de estos procesos, y allí se han realizado proyectos mineros históricos y de gran envergadura que nos llevan a plantear la condición de ciclos de vida de las ciudades asociadas y la vulnerabilidad de sus habitantes ligados a la extracción del recurso.

En la actualidad, dos procesos marcan el modelo de acumulación heredado de las dictaduras latinoamericanas, el cual ha sido consolidado y administrado por los gobiernos posteriores: a) se ha producido un creciente y cada vez mayor interés por el control, la extracción y la exportación a gran escala de los recursos mineros, al abrirse a la inversión transnacional, que en el caso de Chile ha consolidado la imagen de país minero ${ }^{1}$;

b) existe una condición favorable para el posicionamiento del capital privado, tras la salida, auto exclusión y minimización del Estado en estos procesos extractivos y exportadores, generando importantes franquicias y exenciones tributarias para el desarrollo de este sector; disponiendo sus instituciones, aparatos legales, técnicos, sociales y culturales de producción y transferencia, para que se consolide la hegemonía de las transnacionales por sobre la presencia de la minería estatal. Todas estas condiciones son las que reconfiguran los mapas socioproductivos regionales y pueden explicar los cambios en las ciudades mineras y adyacentes que dependen de la explotación de un recurso.

Estas características generales del modelo minero son posibles por un conjunto de reformas regulatorias y sistémicas que operan como facilitadoras para el posicionamiento de las empresas mineras transnacionales, las cuales redefinen la condición de soberanía en términos de control territorial ${ }^{2}$. Ejemplo de ello, es que la II Región de Antofagasta se convierte en el centro mundial de la minería, ya que las más importantes empresas mineras mundiales se encuentran presentes y de manera activa, convirtiendo a Chile entre 1991 y 1998, en el primer país en inversión en exploración y en prospección por $\mathrm{km}^{2}$.

Simultáneamente, también podemos observar:

a) un país que se oferta como país minero y busca permanentemente atraer nuevos capitales;

\footnotetext{
${ }^{1}$ En la actualidad, sólo en la III Región de Atacama, 18 proyectos de inversión minera privados superan los 8.200 millones de dólares. Entre éstos se encuentra Pascua Lama, de la canadiense Barrick Gold, un yacimiento de oro a tajo abierto. En la II Región de Antofagasta, la ampliación de La Escondida, la mina a rajo abierto más grande del mundo, perteneciente a BHP Billiton, tiene una inversión proyectada de 3.250 millones de dólares (Véase Romero y Smith 2009).

${ }^{2}$ Entre éstas: Broken Hill Propietary Inc. (BHP), RTZ Corp., Consorcio japonés JECO, Falconbridge, Minorco, Nippon Mitsui, Exxon Minerals, Phelps Dodge Corp., Sumitomo Corp, Antofagasta Minerals, Placer Dome, Billiton, Boliden, Aur Resourses, Marubeni, Mitsubishi Corp, Xstrata Copper, SQM.
} 


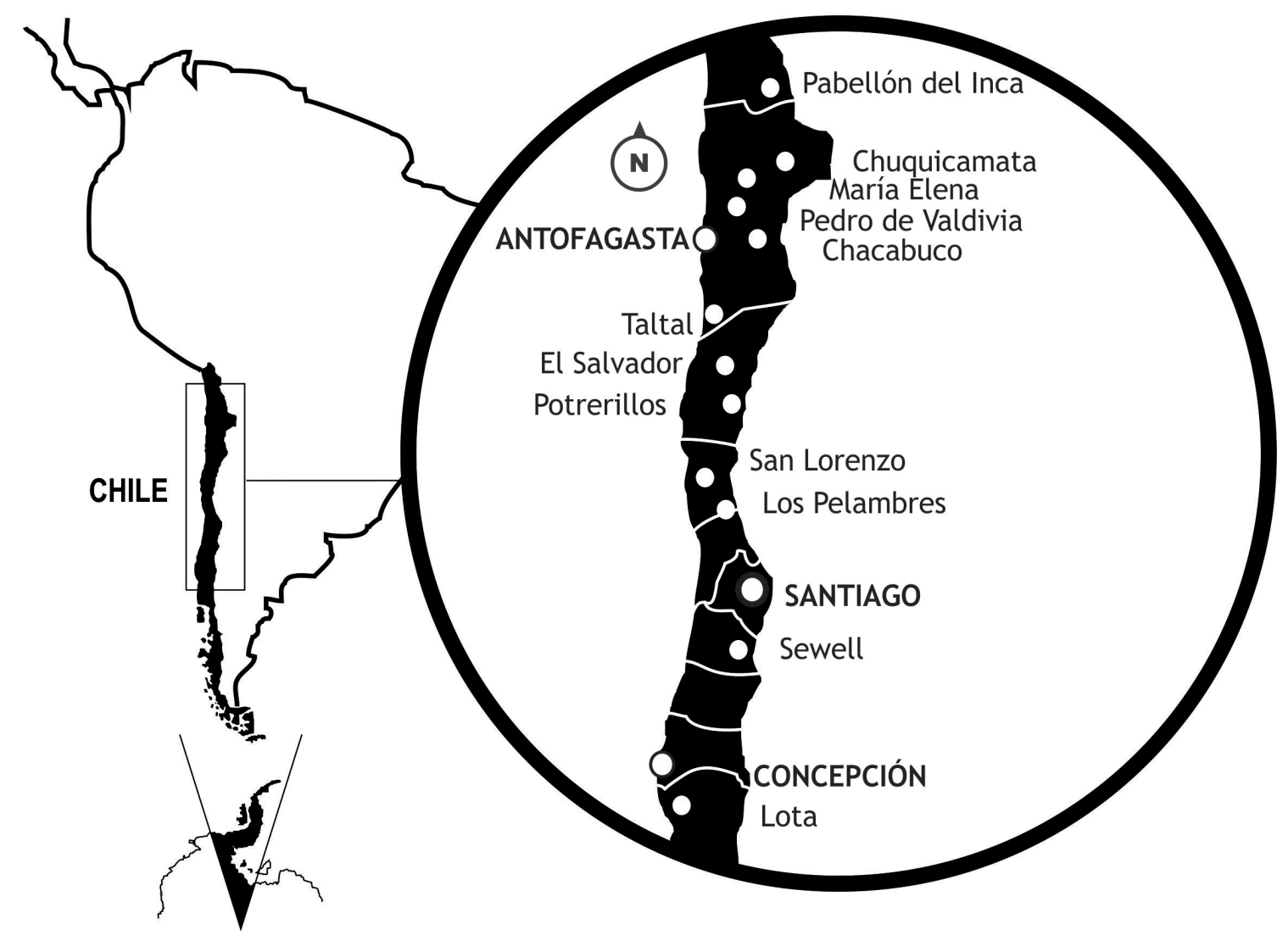

FIGURA 1 - UBICACIÓN DE LAS LOCALIDADES MINERAS CITADAS EN EL TEXTO.

b) mediaciones específicas o lobbies para que se generen las condiciones en distintos niveles de participación en que el capital, el Estado y los operadores se articulen de manera eficiente para "facilitar" la expedición de los proyectos;

c) distintos discursos focalizados a diferentes actores (comunidades, políticos, empresarios), situados en diversos planos (económicos, ambientales, laborales) tendientes a socializar la importancia de los emprendimientos mineros;

d) un ordenamiento territorial específico y cada vez más eficiente y facilitador para interconectar los centros de explotación con caminos y vías que conduzcan hacia fundiciones y puertos; e) una altísima demanda de agua en el proceso productivo, insuficiente para los proyectos mineros, principalmente en el Desierto de Atacama ${ }^{3}$; provocando una degradación medioambiental natural y de las comunidades tradicionales que habitan el territorio, así como la escasez del vital elemento en los centros urbanos;

f) una legislación laboral permisiva, con escasa protección del trabajador, permitiendo modalidades de subcontratación de fuerza de trabajo y una permanente flexibilización numérica y funcional de las plantillas de los trabajadores en los emprendimientos mineros privados.

Es en el entrecruzamiento de estas variables donde acontece la máxima eficiencia del discurso y se produce

\footnotetext{
${ }^{3}$ Es tal la magnitud de la demanda hídrica, que en la costa de la Región de Antofagasta se ejecuta el proyecto de mayor inversión económica del país: una planta desalinizadora de agua de mar de la Empresa BHP Billiton, por un monto de 3.500 millones de dólares.
} 
la sincronización entre la lógica "extractiva" y lo que los nuevos sofistas llaman el "desarrollo sustentable". Sincronía que habla en términos formales, de magnitudes de inversión, de trabajo para la población y de beneficios diversos para las comunidades; es decir, se instala o se insiste en un paradigma de desarrollo que minimiza a través de los dispositivos biopolíticos todas las externalidades sociales y ambientales del paradigma extractivista exportador.

\section{Explotaciones mineras}

En el mundo minero chileno podemos encontrar una diferencia preliminar pero severa: la explotación a gran escala y de cielo abierto, la de la gran minería y, por otra parte, la asociada al socavón o piques en las que participan pequeñas cuadrillas o equipos de trabajo ligadas a trabajadores tradicionales y de poblaciones locales. No obstante, establecida esta diferencia, es importante resaltar que sólo la mega minería provoca un proceso de desnacionalización de la riqueza, debido a que el capital y el producto son administrados en otras latitudes por las corporaciones internacionales; más aun, es tal la magnitud y poder de estas empresas, que por sí mismas pueden definir las características del territorio y el destino y la calidad de vida de los centros urbanos. Por otra parte, las pequeñas unidades de trabajo locales, así como aparecen y se potencian frente a ciclos positivos del valor del mineral, pueden desaparecer cuando los valores se encuentran por debajo de una rentabilidad acorde a los costes de explotación.

La mega minería es permanente, transformando de manera importante el paisaje al afectar en forma superlativa los ecosistemas, no sólo por las faenas en sí, sino porque ésta acumula pasivos ambientales constantes en los territorios. Muy claramente, aumenta hasta lo indecible la demanda de recursos hídricos para realizar los procesos de lixivización de los metales, se acumulan montañas de material removido y se crean tranques de relave que en algunos casos amagan a las comunidades. Esta forma pragmática de alcanzar los objetivos de producción opera de manera binaria, el territorio se sanciona entre uno de tipo viable y otro de carácter inviable; para el capital, viable significa que éste no es más que un territorio eficiente, explotable y rentable, especialmente cuando el Estado ha cedido su poder administrativo y productivo sobre estos territorios; la concepción de territorio inviable, es más bien la de uno que puede ser despojado de todo, es decir, todo cuanto existe puede ser sacrificable, un territorio vaciable (ver SVAMPA, 2010, p. 43). Pareciendo dos lógicas contrapuestas y divergentes, al analizarlas se presentan de manera concordante y unidireccional en torno de la consecución de sus fines: la rentabilidad. Más aún, lo extremo de lo sacrificable o del despojo llega a la minimización y minusvaloración absoluta de las poblaciones, ya sea por escasa densidad y/o por las condiciones de pobreza y vulnerabilidad a las que se encuentran sumidas por décadas, debido a la ausencia concreta del Estado.

De esta manera, y bajo el pretexto de las condiciones de vida precarias de la población, el discurso desarrollista es fortalecido por el slogan de "las posibilidades" a las cuales accederán las comunidades. Por ello, en los emprendimientos de la mega minería hay siempre una narración optimista, expectante y autocomplaciente en una lógica teleológica que asocia la generación de trabajo con bien-estar, desconociendo que las poblaciones locales en general sólo acceden a los empleos menos calificados, ya que estas corporaciones demandan trabajadores ya calificados y no a aquellos por calificar. Entonces, es en este escenario de promesas frente al abandono o retiro del Estado como agente productivo, donde se entrecruzan y amalgaman capital, territorio y comunidades. Por tanto, la pregunta básica es: ¿en qué y cuánto se benefician las poblaciones locales con el emprendimiento minero?

Bajo estas varias aristas e imágenes de dólares, inversión, maquinarias, llamativos vehículos, trabajo, vestuario ad hoc, recaudación de impuestos, patentes, nuevas rutas, ampliación de puertos y movimientos de población, se introduce la idea de un "desierto" que no es físico. Conceptualmente es un Desierto Nuevo; abstracto, que elimina la vida, metafórico, de paisaje yermo, que al minimizar todo lo que ahí existe, salvo la riqueza minera, instala una dificultad para reconocer los derechos territoriales de las comunidades y al derecho que tiene todo hombre y mujer de pertenecer a un lugar en el sentido más pleno de la acepción antropológica: aquella que refiere a la identidad, las relaciones y la historia. Para el capital sólo se trata de un paisaje primario, minimizando y reduciendo todo, lo que constituye la forja de una nueva territorialidad donde opera el lenguaje pragmático de la valoración y de la utilidad.

\section{Nombrar, construir realidades y trabajar}

En el caso de Chile, en la última década, tras los altos precios alcanzados por los commodities, especial- 
mente el cobre (Figura 2) y la discusión en el parlamento sobre el royalty minero (Impuesto Específico a Recursos No Renovables), encontramos la muestra de una narrativa desarrollista inacabable y grandilocuente que sostiene la perversa lógica binaria de los territorios mineros viables e inviables. El lenguaje tecnocrático de las balanzas comerciales, superávit fiscal y la inversión regional, aparece como una forma familiar de nombrar cuando se trata de resaltar los proyectos en ejecución como las obras proyectadas; pero no así lo que nombra el lenguaje antropológico, sociológico, de la psicología social y de la geografía humana, que es el que recoge la biografía de las poblaciones locales en su dimensión diacrónica y en sus quejas, demandas, expectativas y derechos.

La narración trata sobre un imaginario como repertorio de posibilidades y se constituye en real en la medida que alcanza eficacia simbólica, lo que es reforzado cuando hablamos de un país o países con deudas sociales e históricas y cuyos caminos han sido lentos para equilibrar sus balanzas fiscales o servir sus crónicas deudas externas. Entonces, lo que debemos resaltar es que tenemos desde la tecnocracia y la política un régimen monolingüe y una semiología del capital donde la eficacia simbólica del discurso se expresa en una permanente oposición. La institucionalidad del Estado, los gobiernos de turno, la clase política, las autoridades regionales y los lobbystas se encargan de recordar el "antes" y el "ahora", que es parcial como toda capitulación de memoria, ya que resalta y omite. El "antes" se encuentra identificado fundamentalmente con la crisis y con la despreocupación de "otras autoridades" y el "ahora" que se configura por un presente productivo, generador de riqueza, trabajo, bienestar, lleno de promesas y oportunidades. Tenemos una condición "nueva", "luminosa" y "posible", porque hay acuerdos, presencias y materializaciones, aunque las poblaciones sean las víctimas en la configuración de estos "nuevos desiertos".

Lo que tenemos al frente no es sólo una afirmación sobre lo que significa la modificación de la vida colectiva, la división y fractura del tejido social, las prácticas tradicionales, el saber y el hacer propio o el romanticismo antropológico concerniente al valor de la identidad. Contiene una importante omisión: no hay ninguna discusión ni visualización que se presente como intertexto de otro modelo productivo ni de desarrollo de país, ni a nivel regional ni

\section{VALOR DEL COBRE ÚLTIMOS 55 AÑOS}

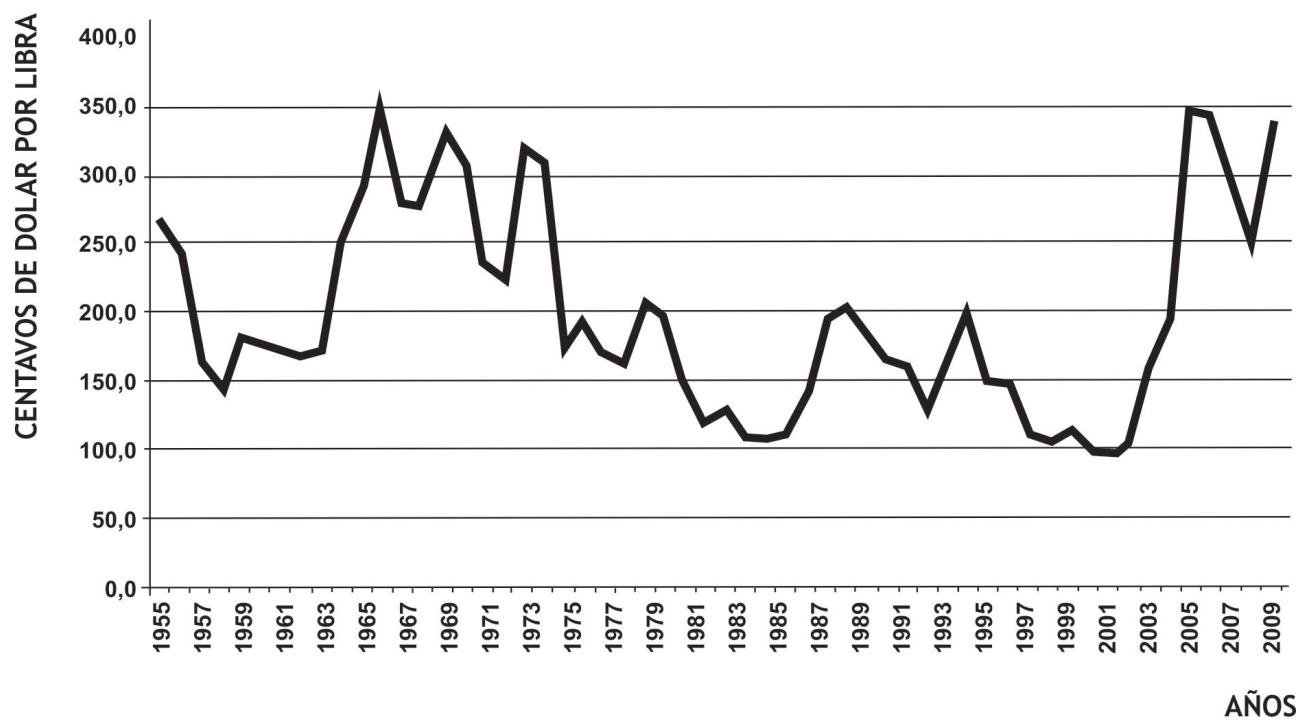

FIGURA 2 - FLUCTUACIONES DEL PRECIO DEL COBRE.

FUENTE: Comisión Chilena del Cobre, COCHILCO. Elaboración de los autores. 
local, que se ubique más allá de las cifras. Entonces, con esta lógica nos ubicamos en una cuestión de tipo simple y básica: el productivismo en su fase primaria.

En relación a lo laboral, la situación de los trabajadores es parte de un sistema adyacente y complementario a estos emprendimientos de la mega minería, ya que la flexibilización, la precarización y la tercerización se vuelven conceptos claves (LA SERNA, 2010; DE LA GARZA, 2006; GORZ, 2000). Según Agacino (1995), el mercado de trabajo chileno presenta claros rasgos estructurales de los cuáles la minería es ampliamente partícipe:

a) la inseguridad laboral es un rasgo permanente;

b) la fuerza laboral está compuesta por un importante número de trabajadores cíclicos, los cuales entran y salen del mercado. Estos, desde la inestabilidad amplían la oferta de mano de obra barata, lo que presiona los salarios siempre a la baja;

c) un importante número de trabajadores se encuentran empobrecidos, laborando en empleos precarios y con bajos niveles de protección social;

d) en los sectores de punta (como el de la mega minería), el salario se encuentra fijado por la productividad, ya que el objetivo es la competitividad;

e) en los sectores productivos de mayor rentabilidad hay una disminución de la plantilla porque se ha incorporado tecnología de punta;

f) existe una disminución del número de obreros y una gran dispersión social;

g) el trabajo se convierte en una cuestión individual y no expresión de fenómenos colectivos, lo que ha debilitado la asociatividad;

h) entre los más jóvenes, tenemos ingresos bajos y cotizaciones provisionales insuficientes, lo que de alguna manera apunta a jubilaciones que se van a ubicar por debajo de la línea de la pobreza;

i) existe un proceso de envejecimiento de la población que trae cambios en la estructura demográfica y que afecta a los sectores activos, ya que se produce un proceso de exclusión por edad, lo que altera el derecho básico a contar con un ingreso;

j) se acentúa la exclusión y la precariedad en la vejez.

En la actualidad, a pesar de lo señalado, el modelo y mapa que se comienza a dibujar en los territorios mineros chilenos, requiere de un nuevo proceso de legitimación social, ya que los dividendos generados por esta explotación minera debiesen expresar una "cierta responsabilidad social" o "responsabilidad social empresarial". Existen empresas, como las señaladas más arriba, que poseen en sus discursos de políticas sustentables, ayudas directas y explícitas a las comunidades cercanas, "apoyando proyectos y actividades conjuntas conducentes a mejorar la calidad de vida de dichas comunidades, enfatizando la educación y la protección del entorno" (SQM, 2005-2006). En algunos casos tenemos asistencias a las comunidades que van desde la electrificación, la construcción de sedes comunitarias, el arreglo de estanques de acumulación de agua potable, vacunación de planteles de animales, el mejoramiento de infraestructura escolar, compensaciones económicas, apertura de caminos, entre muchas otras.

\section{Minería, desarrollo urbano y población}

Los procesos descritos generan un desarrollo desigual en el territorio, ya que aun cuando éste se encuentre definido por su "vocación" minera, los efectos de los enclaves de producción se reproducen en las formas de habitabilidad y ocupación territorial. Lo viable y lo inviable del capital de la minería, en el salitre, en el cobre y en el carbón, implica que centros urbanos y poblaciones completas o parciales, son sacrificables y vaciables en pos del único objetivo estratégico de las empresas trasnacionales: la rentabilidad. Entre los casos emblemáticos, se encuentran los centros urbanos de Pedro de Valdivia, Chacabuco, María Elena, Chuquicamata, El Salvador, Potrerillos, Sewell, Taltal y Lota, entre otras ${ }^{4}$.

Tratándose de centros mineros con características de ciudad, como fueron concebidas las company town, entre las que se encuentran Chuquicamata, María Elena, Pedro de Valdivia, El Salvador y parcialmente Lota; la identidad citadina se consolidó debido a que las compañías mineras tuvieron un gran dominio sobre el conjunto de la vida social. Esto ocurrió porque las organizaciones sociales urbanas necesitaban ser ordenadas, estabilizadas y reguladas a través de reglamentos y también contenidas para evitar aspectos anómicos o disfuncionales a los objetivos productivos.

\footnotetext{
${ }^{4}$ Potrerillos fue una company town ubicada a $2.850 \mathrm{msnm}$, ubicada en la cordillera de la III Región, siendo cerrada de manera definitiva en el año 2.000 , aunque la mina y la explotación de cobre siguen desarrollándose. La ciudad de El Salvador ligada a la explotación cuprífera en la misma zona, aún opera como centro urbano debido a los altos precios del metal; a pesar que se ha proyectado su cierre en los momentos de baja del valor internacional del mineral.
} 
Las compañías explotadoras de cobre, nitratos y carbón diseñaron un mundo profesional cerrado, el cual va de la mano del pleno empleo, como en el caso de los enclaves del cobre y el salitre, que prefiguran una rutina, una estructura, una proyección, un futuro; todo lo cual constituye en última instancia, el único mundo posible para varias generaciones que están dentro de las ciudades-campamentos.

En Chile, las ciudades del salitre (María Elena, Pedro de Valdivia y Chacabuco), las del cobre (Sewell, Chuquicamata, Potrerillos, El Salvador) y del carbón (Lota), revelan un arte de imaginar y hacer ciudad por parte de las empresas propietarias de los complejos urbanos industriales. En lo arquitectónico, que es un elemento diferencial de los centros urbanos industriales, y que los transforma en únicos, hace mirar a sus habitantes "hacia adentro", para acrisolar un permanente doble vínculo que configura una identidad colectiva tanto en el trabajo y fuera de él, aunque segmentada por roles y servicios diferenciados, generando un diseño político que permite establecer una relación emocionalmente segura para sus habitantes, lo que despliega un imaginario asociado a un proyecto de vida.

En su momento, las company town fueron una necesidad para atraer, establecer y retener residencialmente a los trabajadores en las explotaciones mineras, las que debieron conjugar dentro del autarquismo y autosuficiencia que desarrollaron, formas especializadas de trabajo, de asignaciones de vivienda, de servicios alimentarios, recreacionales, sanitarios y educativos, es decir, a veces en exceso o en sobreabundancia, proveyeron todo lo requerido para estabilizar a la población.

No obstante la eficiencia de esta fórmula demostrada por décadas y la valorización que hacen las personas sobre este modo de vida seguro, este modelo entra en crisis y se pone en retirada cuando las empresas incorporan criterios más rígidos de eficiencia y rentabilidad, al incorporar la lógica binaria de lo viable y lo inviable, y por tanto lo sacrificable como fundamento para ser más competitivas; afectando los modos de vida comunitarios, construidos a través de décadas o generaciones. En los casos extremos de lo sacrificable, se termina de manera definitiva con el vínculo entre el hombre y el territorio en el caso de las Oficinas Salitreras del Norte Grande. Con el cierre de ellas, se pone el fin de un modelo de habitar el territorio que sincronizaba las instalaciones industriales, habitacionales y los proyectos de vida de una comunidad.

Los ingentes desarrollos tecnológicos y nuevos desafíos de competitividad y eficiencia son los que entran a cuestionar el formato de este tipo de ciudad y el saber hacer de las poblaciones mineras tradicionales, dejándolas poco a poco en una condición de fuera de lugar, al margen, como residuales, ya que cada vez se requieren menos trabajadores y más calificados para las actividades extractivas y productivas.

\section{Ciudades del salitre: María Elena y Pedro de Valdivia}

El desierto más árido del mundo, el de Atacama, desde el siglo XIX ha revelado que en el paisaje yermo existe más que la infinita soledad y esterilidad que entrega una primera aproximación. Es un paisaje que se constituyó en territorio por la magnitud de la riqueza minera que esconde. Los rasgos de desolación, lo inerte y la ausencia de precipitaciones, sólo pudieron superarse por emprendimientos pioneros, movilizando instrumentos de producción y una importante fuerza de trabajo traída desde el centro sur de Chile y de países vecinos como Bolivia y del noroeste de Argentina. Cientos y miles de almas dieron forma a una red de "oficinas", que es el nombre técnico que define los emplazamientos habitacionales e industriales donde realizaron la vida los obreros y profesionales venidos principalmente desde Europa. Las Oficinas Salitreras marcaron el territorio con presencia humana, instrumentos de trabajo e infraestructura industrial, ligadas a líneas troncales y ramales de ferrocarril que interconectaron puertos y los enclaves extractivos, llevando salitre y trayendo insumos domésticos e industriales, dando vida a una manifestación cultural sui generis, "la cultura pampina". Esto es, a una forma de vida, de agregación y sociabilidad particular de hombres y mujeres que fueron transplantados desde otros paisajes y experiencias cognitivas y valóricas, quienes sin ver un hilo de verde, con el correr del tiempo se fueron quedando sin posibilidades de retorno a sus lugares de orígenes; hicieron su vida de manera entrópica y conforme a las posibilidades del paisaje, a una actividad monoproductora y exclusiva, formaron familias y elaboraron sus proyectos de vida, enterraron a sus deudos, en un contexto donde hasta las tres primeras décadas del siglo XX, el trabajo fue esencialmente manual y de gran esfuerzo físico.

Esta cultura de la pampa vinculada a la industria que explotaba nitrato, del cual se derivaba pólvora y se producía salitre para fertilizante, se desarrolló sobre la base de concentración de población, con participación de personas no 
productivas como niños, mujeres y ancianos, mano de obra extensiva, el uso de mulas para los obrajes, alta demanda de forraje y combustible para hacer hervir los caldos. La rusticidad de los procesos desarrollados por la industria hasta los años 20 `s del siglo pasado, implicó siempre altos costes productivos y trabajo con mineral de alta ley. Esta situación se hizo insostenible, colapsando con la depresión del año 29 y con la invención paralela del salitre sintético, lo que convirtió el territorio en un paisaje desolado y sin posibilidades de habitación por parte de trabajadores y sus familias. De esto, sólo queda la ruina y la desolación como testimonios y el mito como memoria colectiva.

Es en este estrecho derrotero donde aparece un nuevo formato industrial y habitacional: las ciudades del salitre. Éstas, obedecen a una razón utópica y a una planificación pormenorizada; se trata de la ciudad ideal que es concebida sobre una hoja en blanco, de acuerdo a los principios del urbanismo moderno. María Elena construida entre 19251926 por capitales privados, en la que no se dejó detalle al azar, albergó a 10.000 personas en pleno Desierto de Atacama, al igual que su par Pedro de Valdivia, construida entre 1930-1931, con una población similar y distante a 30 kilómetros.

¿Qué encontramos en ellas? Todo aquello que define a las company town. Pero, muy particularmente y más allá de la funcionalidad productiva, una relación con el ocio y el tiempo libre; teatro, cine, música, deportes, educación, espectáculos internacionales, bailes y fiestas saturan el espacio social y hacen visibles a todos sus habitantes. Es el conjunto de actividades en el espacio cerrado, privado y exclusivo el que nos indica no sólo cuántos son los habitantes, sino en qué actividad se encuentran y dónde están. Aunque la construcción es panóptica, el control espacial y temporal entre actividades sociales y productivas es lo que ofrece la estabilidad y el sentido de pertenencia de sus habitantes de estas dos ciudades, dando forma a un imaginario del "privilegio", del ser elegido para vivir ahí y beneficiado con la estabilidad sincrónica que proporciona la relación entre trabajo, vivienda y alimentación (Figura 3).

Con este ejemplo, rescatado de nuestros trabajos etnográficos, tratamos de resaltar dos cosas: la primera, referida a la subjetividad del habitante y su reconocimiento

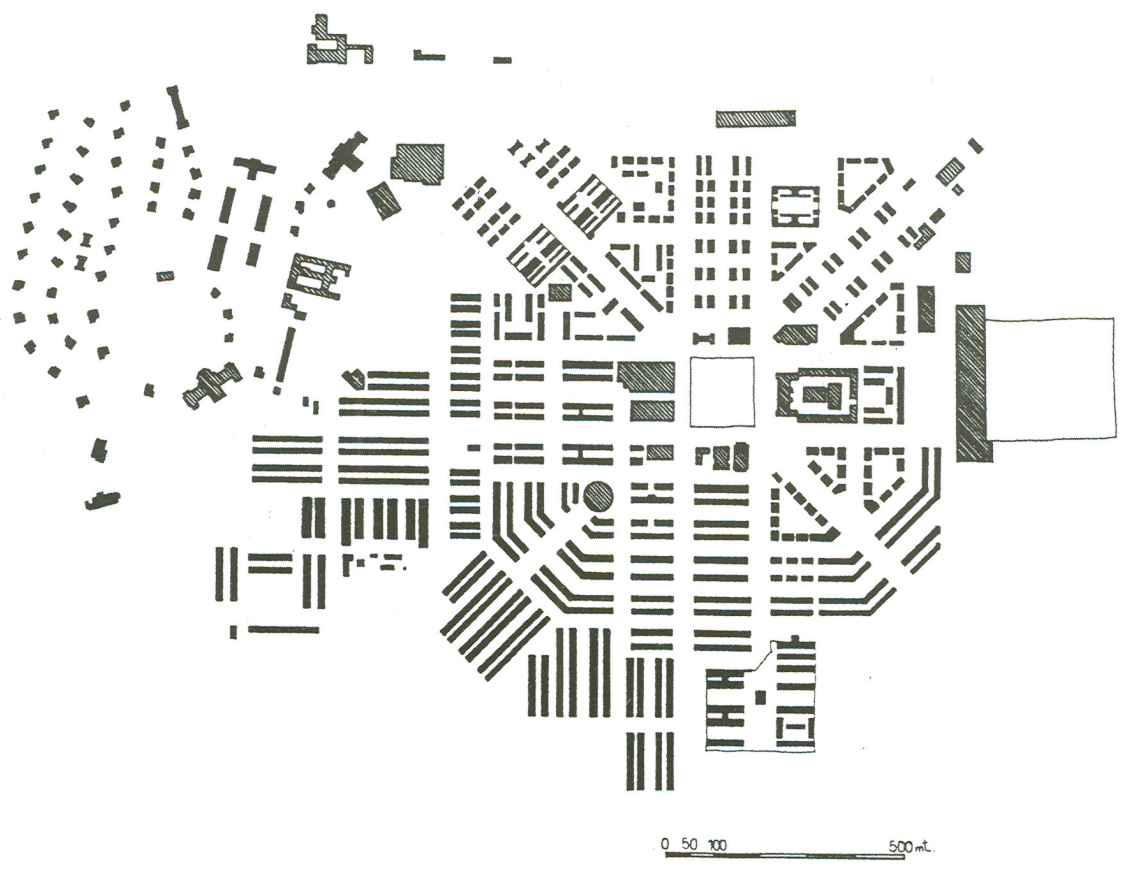

FIGURA 3 - PLANTA URBANA DE MARÍA ELENA. 
social, sentido de pertenencia y arraigo que estimula este formato utópico de las company town, ya que muy pocos de ellos alguna vez se plantearon la posibilidad de irse de las ciudades; la segunda, referida a la rentabilidad económica de las compañías que impacta sobre esta utopía. En este último sentido, no es sino la lógica de la maximización de beneficios la que se impone sobre la imagen de totalidad que hemos detallado, que es precisamente lo que instala el juego de lo viable e inviable y la decisión sobre lo "sacrificable" o lo "vaciable". Y es, precisamente la privatización de ambos complejos urbanos industriales en 1988, lo que define lo sacrificable: el tamaño de la ciudad, el número de habitantes y los servicios que se prestan a su población.

Sobre María Elena, desde el momento de la privatización se discute su condición de "ciudad". Cada día, ésta es menos ciudad, cada día es más campamento minero, es decir, de ocupación transitoria. La estrategia empleada por la empresa propietaria SQM para redefinir su funcionalidad en pos de la rentabilidad, es disminuyendo su número de habitantes a través de la implementación de una nueva filosofía del trabajo, compuesta por la introducción del criterio de la flexibilidad funcional y numérica de la plantilla de trabajadores ${ }^{5}$. Se trata del fin del pleno empleo que justificó la fundación de la ciudad, la redefinición y rotación de roles o plurifuncionalidad entre los trabajadores de la Compañía y de nuevos contratos, esta vez de subcontratados. Es decir, la plantilla aumenta o disminuye en función de cuestiones sólo económicas, ligadas a la expansión de la demanda de productos explotados y elaborados.

Con tal filosofía, la ciudad se resiente en su tejido social, en el conocimiento mutuo y en la confianza básica. Los subcontratados sólo vienen a trabajar por períodos específicos y el producto de su trabajo se gasta y consume en otras ciudades o regiones donde están sus familias, lo que deprime a todo el pequeño comercio local, ya que estos trabajadores no históricos, duermen y se alimentan al margen de la ciudad con sistemas all inclusive. A ello, se suma una política de incentivos para que las familias tradicionales abandonen la ciudad, con ofertas en dinero, ayuda para traslados, compras de viviendas en ciudades y regiones cercanas. Económicamente para la Compañía SQM, lo sacrificable es una casa familiar que demanda agua, luz y servicios de mantenimiento, que distraen recursos y personal de esta Compañía internacionalizada, cuestión que no se encuentra en el horizonte de sus convicciones.
Entonces, lo que era una ciudad, se convierte en un paisaje de trabajadores solteros que mantienen una relación atópica con la ciudad; producen ahí, pero el imaginario de su proyecto de vida se encuentra en otro lado, porque sus familias y sus residencias están fuera de María Elena, ya que la condición de permanencia está asociada al trabajo en distintas modalidades de turnos. Se trata sólo de ir y venir por un número de días.

Su alter ego, Pedro de Valdivia, construida según los mismos principios utópicos, sólo existe como ruina. Una ordenanza de la empresa propietaria del complejo urbano en el que vivían cientos de familias, decretó su cierre entre 1995 y 1996, cortando todo tipo de servicios como agua y luz. La empresa notificó su decisión sin consulta a los habitantes de manera indeclinable, facilitó camiones para el traslado de las familias a las ciudades adyacentes y cada día se iban apagando las luces de una y otra casa, de una cuadra y otra, hasta que la ciudad quedó en la obscuridad total. La ciudad mostró sus vértebras al aire, saqueada, afásica; sin jugadores en el estadio de fútbol y el gimnasio, sin fieles en la iglesia, sin niños en la escuela y la biblioteca, sin pacientes en el hospital, sin viejos en la plaza, sin vendedores y compradores en el mercado, sin la sirena que anunciaba que es mediodía. El cierre irreversible, feroz, violento, diseminó por todos los caminos a la subcultura de los trabajadores del salitre; pero, en este caso, la determinación no sólo los dejó sin ciudad y sin vida cotidiana local, sino que los desarraigó del desierto y de la tradición minera salitrera. Quedaron como pampinos y pampinas fuera de la pampa, es decir, exiliados de su relación con el paisaje y la convivencia.

En ambos casos, las ciudades del salitre como lugares de interacciones son sólo puntos en el mapa que no tienen nada que ver con las decisiones y los intereses de una junta de accionistas. La eficiencia productiva se encuentra ligada a la posición que éstas tienen en la economía regional, nacional y mundial, sólo están convocadas a ser eficientes y rentables en cuanto organización productiva y no social. Lo social, lo cultural y lo comunitario corresponde a lo que hemos llamado sacrificable y pragmáticamente se amontona, como los acopios de residuos del mineral, como otra externalidad más del modelo productivo. En este esquema, no hay lugar para el ocio, las personas improductivas, mantener viviendas y subsidiar una ciudad.

\footnotetext{
${ }^{5}$ Se estima que al año 2015 la población estable disminuirá de los poco más de 5.000 habitantes a unos 2.500 .
} 


\section{Lota: la ciudad del carbón}

En el caso de la ciudad de Lota, la primera urbe industrial del país, ésta es hija de la mina. Se desarrolló a partir de un pequeño poblado establecido en 1852, la que creció en función de las actividades extractivas. Antes que en la Capital, se implementa la telefonía de superficie y subterránea en los túneles, producto de la potencialidad del trabajo extractivo de carbón, también se instala el alumbrado público y privado con una planta hidroeléctrica, redes de gas, calefacción domiciliaría, ascensores para bajar y subir a los piques, un tren subterráneo para conducir a los trabajadores y extraer el mineral. A partir de la explotación del carbón, se produce una integración productiva que hoy llamaríamos un holding, compuesto por la empresa minera, una flota de transporte naviero, ferrocarriles de superficie, muelles y emplazamientos portuarios, una fábrica productora de vidrio, de cañerías, de ladrillos refractarios para las fundiciones de cobre y de cerámica doméstica y ornamental, una industria forestal para contar con madera para el trabajo en la mina.

En la Lota floreciente de la segunda mitad del siglo XIX se podían encontrar construcciones industriales monumentales, división funcional y estratificada de la ciudad y sus barrios, barcos, muelles, tren, teatro, hospital, estadio, clubes, jardines, árboles exógenos, esculturas, piletas, aves exóticas; todo pensado como conjunto armónico y de manera estratégicamente integrada, constituyendo el paisaje único de esta ciudad perfilada como gris por el humo de las chimeneas de su fundición y las múltiples de los hogares. En el siglo XIX se hablaban muchas lenguas por sus calles, era una ciudad políglota, con arquitectura inglesa e iglesias y pastores protestantes venidos desde Europa que deambulaban por ahí junto a técnicos e ingenieros extranjeros y los mineros.

Después de casi 150 años de explotación submarina, las minas de Carbón se cerraron el año 1997, aunque la matriz energética del país que alimentaba a la industria naviera, siderúrgica y ferroviaria con carbón, ya había cambiado en 1950 con la introducción de la hidroelectricidad y el petróleo. La actividad era declinante desde el punto de vista de la demanda y de los costes productivos, no así desde el imaginario y desde el trabajo especializado, ya que lo que existía y persiste es la figura de una cultura del trabajo. Hablamos de cultura del trabajo porque la mina corresponde a un mundo de entregas y ruegos que se exploraba cada día, pero que nunca se terminó por dominar, ya que los hombres que bajaban al territorio de la subterra en los distintos turnos se desvinculaban hasta 12 horas diarias del ajetreo de la ciudad, del "subsole". La mina era un territorio de trabajo en equipo, de confianzas en el compañero, de autocontrol, de templanza, de arrojo, de construcción de un territorio, lleno de episodios infaustos; se requería de habilidad y fuerza física para el trabajo, lo que modeló los cuerpos que se estilizaron y se llenaron de heridas lacerantes, de extremidades amputadas, de pulmones saturados de polvo. Estas particularidades son las que han marcado una línea de comprensión de lo que ha sido la vida de los obreros del carbón y sus familias, como un ícono que permanece en la retina del mundo escolar y de los chilenos durante generaciones (Figura 4).

Con el decreto de cierre que manifiesta la inviabilidad de la explotación y el desinterés del Estado por subsidiar el proceso extractivo, se puso fin de manera definitiva a la actividad desarrollada por generaciones, la que operaba con un sistema de tres turnos sucesivos de relevo; se cerraron los piques, se remató la maquinaria e inundó de agua los túneles que avanzaban 15 kilómetros bajo el océano, de modo que nunca más ingresaran trabajadores a laborar. La ciudad se deprimió en términos demográficos, pasando de 80.000 habitantes en los años 80 's a menos de 50.000 en la actualidad. Todos en la ciudad monoproductora, directa o indirectamente vivían en torno al trabajo carbonífero. Tras el cierre, hubo un plan de reconversión laboral que pretendió reciclar la experticia de sus trabajadores, es decir, de su saber hacer. Este plan, en términos formales trataba de reincorporar laboralmente a los trabajadores, los que teniendo una especialidad se encontraban impedidos de continuar ejerciéndola por razones externas a ellos y sin posibilidades de permanecer en el mercado de trabajo con dicho perfil ocupacional; se estimularon emprendimientos hacia áreas de la mueblería, el transporte, la gastronomía y el comercio. Este proceso fracasó en gran medida por la poca ductilidad que ofrecía la especialización de sus trabajadores, las enfermedades profesionales heredadas, como la silicosis, artritis y problemas lumbares, así como por el bajo interés por reemprender nuevas actividades.

Desde que se decretó el cierre de las minas y el fin de las actividades por parte de la empresa ENACAR ${ }^{6}$, una empresa del Estado, son actualmente unos 4.000 los em-

${ }^{6}$ Empresa Nacional del Carbón. 


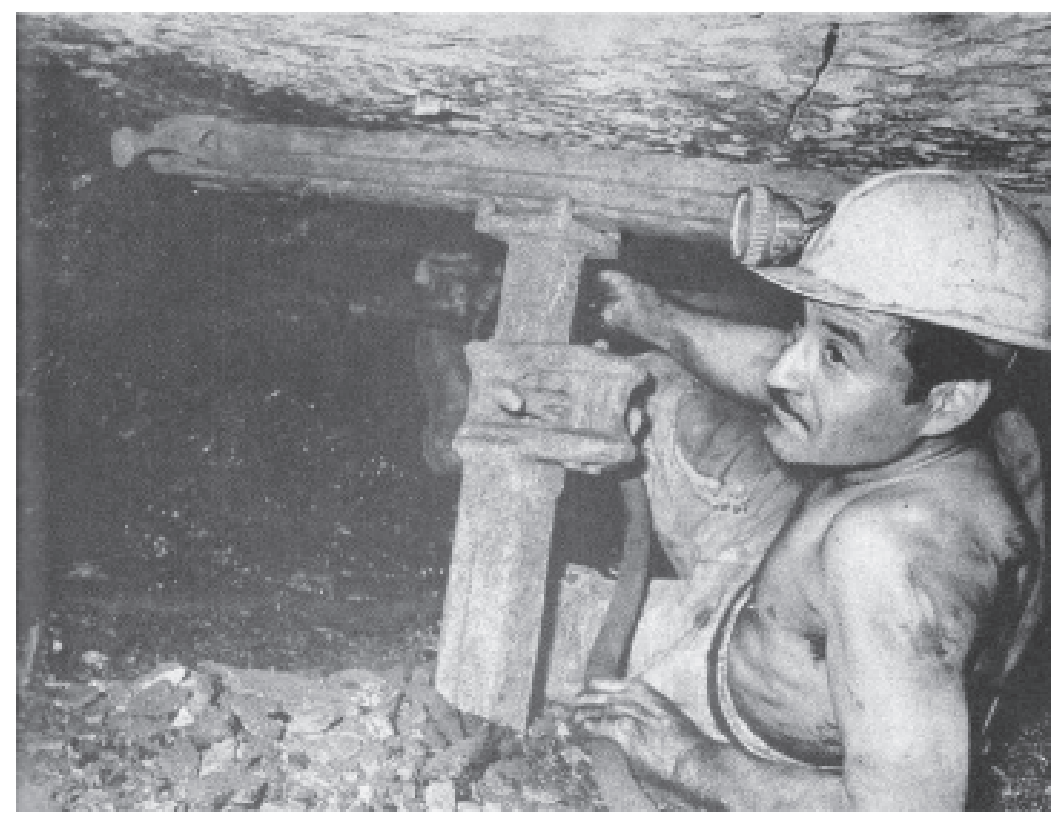

FIGURA 4 - MINERO DEL CARBÓN EN LOTA.

pleos subsidiados por el Estado, pero ninguno de carácter productivo, a los que se suman hombres jubilados antes de cumplir 40 años de edad. Los ex trabajadores deambulan en la urbe y no se motivan por ninguna otra actividad que no sea lo minero, ni tampoco quieren moverse de su ciudad; su vida es en relación a Lota y el imaginario se ubica en la mina. Todo otro trabajo es considerado de segundo orden; los hombres se quedaron sin disciplina laboral, porque no hay lugar para su saber hacer.

Hoy Lota destaca por sus ruinas de lo que fue su mina y sus patrimonios asociados a la actividad extractiva y productiva, así como por las grandes trasformaciones culturales y laborales que han cambiado el quehacer económico cotidiano. Destacando, entre otras cosas, el paso de una familia sostenida por el minero, a otra donde son las mujeres las que han salido a trabajar, principalmente en servicios y ventas en la feria libre de la ciudad, forjando un espacio de visibilización femenina, que nos lleva a pensar en una feminización de la ciudad, tradicionalmente patriarcal y machista.

La historia de Lota es la de una ciudad que, finalmente, como todas las ciudades mineras, nunca dependió de ella misma sino de factores externos como la matriz energética del país y la demanda externa y, una vez que se decreta el cierre definitivo de la actividad extractiva, sus formas de trabajo desaparecen como saber hacer y con ello la ciudad entra en deterioro, ruina y declinación. Para los hombres del carbón no es fácil reorganizar la vida ni esclarecer desde dónde y con qué argumentos se puede reemprender un camino para encontrar un nuevo sentido a la existencia, cuando su territorio laboral, ligado al subterra, ha desaparecido. Tampoco es sencillo señalar con claridad cuánto de la experiencia y qué acontecimientos se pueden sacar de la memoria para que las incomodidades provocadas por la alteración de su singularidad se mitiguen para que lo no resuelto encuentre otras opciones (RODRÍGUEZ; 2010; MEDINA 2010).

Si ya es difícil dar respuestas existenciales a este drama de hombres que no encuentran su lugar en su localidad, sorprende más aún, que los agentes del Estado, municipal, regional y nacional, no tengan respuestas ni caminos para la ciudad y sus habitantes.

\section{Chuquicamata: la ciudad emblemática}

Chuquicamata, ciudad ligada a la mina del mismo nombre y que inicia la explotación de cobre en 1915, constituye la ciudad minera más importante y emblemática del Desierto de Atacama donde habitaron trabajadores y 
sus familias. Dos factores terminaron en el año 2007 con la urbe y la sociabilidad construida por décadas: primero, en 1992 se le define como un área saturada de material particulado respirable (anhídrido sulfúrico) y altos índices de arsénico; en segundo lugar, CODELCO, la cuprífera estatal, evalúa la necesidad de expandir las faenas hacia el territorio ocupado por la ciudad.

En un largo proceso que tomó más de una década, las faenas, de lo que fue en su momento la mina a tajo abierto más grande del mundo, avanzaron sobre la ciudad hasta que se hizo imposible mantener a la población que tenía sus casas en comodato, dando paso a un proceso de erradicación y de demolición de las viviendas y la infraestructura. Se va el Regimiento $\mathrm{N}^{\circ} 1$ de Chuquicamata, se cierra su Hospital Roy H. Glover en el año 2001, se pone fin al comercio y se trasladan las escuelas. Este camino forzado y no expedito, resistido y doloroso, no hace más que revelar cómo el capital se ubica más allá de los sentimientos de pertenencia y arraigo que las personas desarrollan, de los lugares de referencia, de las sociabilidades, de los sentimientos comunes y memorias, de las historias.

La población, so pretexto de una situación inevitable y de una mejor expectativa de vida, fue relocalizada en Calama, ciudad adyacente y considerada siempre "secundaria" para los habitantes históricos de "Chuqui", la que siempre constituyó su alter ego degradado e inferiorizado. Aquí, en un intento por restablecer lo perdido, destruido y siniestrado, la salida fue la creación de una nueva ciudad para los erradicados: "la Nueva Calama". A varios años del doloroso proceso de erradicación, las quejas se oyen por doquier, no por lo nuevo, sino por lo perdido. Ello es lo sacrificable y vaciable por parte de la empresa y, en segundo plano permanecen, sólo como recuerdos, los clubes exclusivos, los barrios, los vecinos, el teatro, la escuela, los almacenes y las viviendas históricas con las que se convivió por décadas.

\section{Taltal: después del ciclo salitrero}

Un ejemplo emblemático, pero diferente, lo constituye la ciudad puerto de Taltal, enclavada entre el mar y el Desierto de Atacama. A pesar de su lejanía y aislamiento de las principales ciudades fue considerada una ciudad hiperconectada, con ferrocarril, muelles de embarque de pasajeros y carga, aeródromo y carretera adyacente. $\mathrm{Su}$ posición fue estratégica para la explotación del nitrato ya que fue el puerto de embarque del salitre en una macrozona integrada por oficinas habitadas por unas 30.000 personas. El centro urbano salitrero debió reconvertirse a la pequeña minería del cobre, una vez que fue cerrado el Cantón salitrero ${ }^{7}$ del mismo nombre, cuando de acuerdo a los antecedentes indicados más arriba, se hace inviable la rentabilidad de la producción a fines de los 50's y comienzos de los 60's, perdiendo su conectividad marina, ferrocarrilera y aérea. Atrás quedó la ciudad multilingüe, sus muelles, la treintena de clipers anclados en su bahía, el ferrocarril, las casas de estibaje, los bancos, las suscripciones a periódicos de diversas partes del mundo, el glamour de su club inglés y su arquitectura señorial. Hoy, la ciudad se deforma y se contrae demográficamente de acuerdo a los ciclos mineros, ya que lo que sucede internamente depende del valor internacional de la libra de cobre. Es decir, es tal su dependencia de las condiciones externas que disminuye su población desde unas 12.000 a 14 o 15.000 personas hasta los 5.000 habitantes en la década de los años 90's, transformando a casi el $20 \%$ de su población, de sus trabajos productivos a empleados municipales ocupados en labores de servicios.

A la ciudad de Taltal, lo único que la mantiene viva es la fuerza del imaginario de los mineros históricos, que son emprendedores independientes: creen que pueden hacerse ricos, encontrando una gran veta de cobre, plata u oro, actualizando permanentemente el sueño de El Dorado. Mientras la ciudad declina en lo cultural y lo educacional, se produce un proceso inverso en lo laboral, ya que hoy la habitan 13.000 personas que aprovechan y viven del excelente precio internacional del cobre. A pesar de estar presionada por su aislamiento entre las desolaciones del mar y del desierto, Taltal subsiste alejada de las compañías transnacionales, permitiendo que sus mineros locales vendan el recurso a la estatal Empresa Nacional de Minería, ENAMI.

\section{Comentarios finales}

Las ciudades mineras nos hablan de cómo el capital en su maximización, genera divisiones tópicas de territorios viables e inviables, sin considerar las consecuencias en las poblaciones y las ciudades ligadas a las actividades extractivas. Además, podemos numerar: alteraciones en la demografía, en los índices de masculinidad, en la inversión

${ }^{7}$ El Cantón salitrero de Taltal incluía unas dieciocho oficinas salitreras. 
pública y privada, diferenciación entre generaciones, obsolescencia de algunas identidades laborales, fracturas en las orientaciones de la socialización, pérdida de prestigio de actores históricos, alteración de los espacios extralaborales (RODRÍGUEZ, 2010).

De acuerdo a las experiencia urbanas descritas, existe un "ciclo de vida" de la explotación minera, de las tecnologías, de los productos y de las formas de ocupación territorial, lo que expresa básicamente los cambios en la demanda micro y macro-económica y la disponibilidad y evaluación de la ley del mineral. Esto se encuentra asociado a una fase donde se consolida el proceso de ampliación de los mercados, el cual siempre tiene ciertos límites que pueden ser impredecibles, hasta el estancamiento de la demanda por efecto de la competencia interna o externa y también por la aparición de otras formas tecnológicas o productivas más eficientes. Esto tendrá impacto en las formas de trabajo, en las posibilidades y proyectos de sus gentes.

El modelo primario de explotación y exportación minera es de tipo de acción total, al afectar múltiples áreas: territoriales, geográficas, ecosistémicas, sociales, culturales, demográficas. Nos habla del poder que tienen las corporaciones trasnacionales al reconfigurar la composición cultural y la magnitud de las poblaciones locales. Trae consigo problemas sociales, ambientales y sanitarios que impactan sobre las condiciones de vida y sobre las formas de ocupación del territorio. También, a través de la llamada responsabilidad social empresarial, las compañías amplían sus bases de interés, superan la presencia del Estado y se convierten en los principales agentes de socialización en las comunidades.

Los nuevos formatos habitacionales ya no son ciudades sino campamentos. Los más nuevos definitivamente tienen una concepción hotelera: aislados, diseñados para sistemas de turnos, una ocupación de instalaciones de máxima eficiencia y con todo aquello necesario para trabajar y distraerse sin entrar en crisis. Estos últimos, de alta inversión como San Lorenzo (1995), Pabellón del Inca (1999) y Los Pelambres (2000), constituyen islas en la pampa y las montañas, ya que son sólo lugares para trabajar y dónde sólo se conoce a los compañeros de turno, por lo que se juntan en torno a las labores y separan una vez realizadas las faenas.

\section{Bibliografía}

AGACINO, Rafael. Todo lo flexible se desvanece. El caso chileno. En: AGACINO, R.; ECHEVERRIA, M. (Eds.). Flexibilidad y condiciones de trabajo precarias. Santiago: PET, 1995.

DE LA GARZA, Enrique. Teorías sociales y estudios del trabajo: nuevos enfoques. España: Editorial Anthropos y Universidad Autónoma Metropolitana, 2006.

GORZ, André. Miserias del presente y riqueza de lo posible. Buenos Aires: Paidós Editorial, 2000.

LA SERNA, Carlos. La transformación del mundo del trabajo. Representaciones, prácticas e identidades. Buenos Aires: Ediciones Ciccus, Clacso, 2010.

MEDINA, Patricio. La espera como forma alienada del sufrimiento humano. La historia interrumpida de un pueblo minero. En: BILBAO, Alejandro; MORLANS, Ignacio (Eds.). Duelo, pérdida y separación: figuras del sufrimiento humano. Valparaíso, Chile: Ediciones Universitarias de Valparaíso, 2010. p. 117-128.

RODRÍGUEZ TORRENT, Juan. Notas para la ciudad de la nostalgia. Potosí: de la fiesta a los fantasmas. En: . Antropología, estudios de medio ambiente y urbanismo. México: Instituto de Investigaciones Antropológicas, UNAM, 2002.
De la ciudad del trabajo a la ciudad del vacío: el lugar del sufrimiento. En: BILBAO, Alejandro; MORLANS, Ignacio (Eds.). Duelo, pérdida y separación: figuras del sufrimiento humano. Valparaíso, Chile: Ediciones Universitarias de Valparaíso, 2010. p. 91-106.

ROMERO; SMITH. Patrones emergentes de localización de inversiones productivas en las regiones extremas de Chile: nuevos desafíos ambientales. Chile, 2009. Disponible en: $<$ http://200.89.70.78:8080/jspui/handle/2250/10282?mode=f ull\&submit_simple $=$ Mostrar+registro+completo $+>$.

SQM, 2005-2006 Memoria Social. Santiago-Antofagasta.

SVAMPA, Maristella; BOTTARDO, Lorena; SOLA, Marian. La problemática de la minería metalífera a cielo abierto: modelo de desarrollo, territorio y discursos dominantes. En: SVAMPA, Maristella; ANTONELLI, Mirta (Eds.). Minería transnacional, narrativas del desarrollo y resistencias sociales. Buenos Aires: Editorial Biblos, 2009.

Recebido em setembro de 2011. Aceito em novembro de 2011. Publicado em dezembro de 2011. 